Proceedings of the $\mathbf{2}^{\text {nd }}$ ICEENG Conference, 23-25 Nov. 1999

\begin{tabular}{|l|l|}
\hline $\mathrm{AW}-5$ & 1 \\
\hline
\end{tabular}

Military Technical College Kobry Elkobbah, Cairo, Egypt

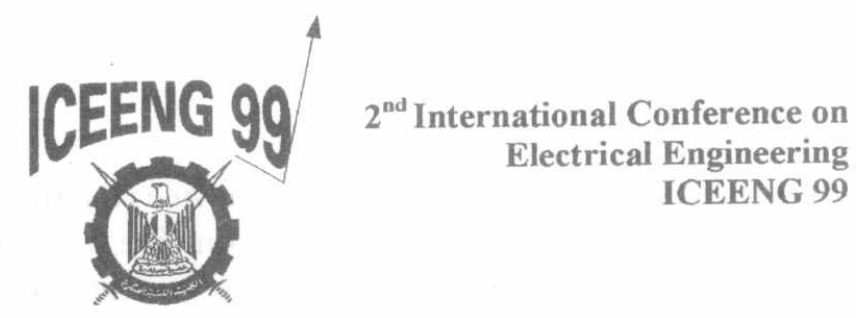

\title{
DESIGN AND IMPLEMENTATION OF A 2 GHZ ACTIVE INTEGRATED ANTENNA
}

\author{
Hosny A. El-motaafy *, Abdel Rahman Sallam **
}

\begin{abstract}
This paper presents the design and implementation of a $2 \mathrm{GHz}$ active integrated antenna module. The module comprises a microwave amplifier, a 3-dB hybrid coupler, and a microstrip-patch antenna.

The module is implemented using the microstrip-line technology. It gives a performance that is very close to the theoretical one. This module can be used in many applications such as active and semi-active seekers, satellite communication, radio altimeters, missile technology, weapon fuzing, manpack equipment, remote sensing, and biomedical radiators.
\end{abstract}

\section{KEY WORDS}

Microwave amplifier, active integrated antenna, microstrip patch antenna

- *Dept. of Electronics and Computer Engineering, Higher Tech. Institute, $10^{\text {th }}$ of Ramadan City

- **Dept of Microwave, National Institute for Standard, El-Haram, Giza. 
Proceedings of the $2^{\text {nd }}$ ICEENG Conference, 23-25 Nov. 1999



\section{INTRODUCTION}

An active antenna integrates an active device (microwave diodes or transistors) into a printed antenna to improve its performance or combine functions within the antenna itself. Therefore, complete transceiver modules can be implemented in a single substrate. Such modules are of increasing interest, as system designers require more complex functions to be implemented in reduced space [1-6]. The application of such active antennas comprises active and semi-active seekers, remote sensors, collision avoidance radars, wireless local-area networks, ..etc.

The module designed and presented in this paper comprises an amplifier designed to operate at a frequency of $2 \mathrm{GHz}$, a $3-\mathrm{dB}$ directional coupler, and a patch antenna resonant at $2 \mathrm{GHz}$ The module is designed and implemented using microstrip-line technology.

The module is implemented and tested in the National Research Center [NCR]. The block diagram and the layout of the module are given in Figs. 1 and 2 respectively.

\section{Design of the High-Gain Microwave Amplifier}

The block diagram of the designed amplifier is given in Fig. 3. The active element used in the design is the low-cost general-purpose transistor HXTR-3101. The dc-operating point is chosen at $V_{C E}=10 \mathrm{~V}$ and $I_{C}=15 \mathrm{~mA}$. The transistor was found to be unconditionally stable at the operating point. The equations used in the design and the CAD program employed are described in detail elsewhere [7-9]. The designed module comprises a 3-dB hybrid coupler in order that the amplifier can be tested irrespective of the attached antenna. The entire module is implemented using a microstrip substrate that has the following specifications

Relative dielectric constant $\varepsilon_{r}=6$

Height of the dielectric material $h=0.635 \mathrm{~mm}$.

Strip line thickness $t=0.035 \mathrm{~mm}$

The amplifier is tested in the NRC. Its measured power gain was found to be $11.35 \mathrm{~dB}$

At $f=2 \mathrm{GHz}$. The bandwidth was $193 \mathrm{MHz}$.

\section{Design of the Microstrip Patch Antenna}

A microstrip patch antenna (MPA) consists of a conducting patch of any planar geometry on one side of a dielectric substrate backed by a ground plane on the other side [4]. Such antennas received considerable attention starting in $1970 \mathrm{~s}[3]$ and are used now to implernent hybrid MIC and MMIC transceiver modules [6]. The microstrip antennas are low profile, conformable to planar and nonplanar surfaces, simple and inexpensive to manufacture using printed circuit technology, mechanically robust and very versatile in terms of resonanct frequency, polarization, pattern and impedance. There are numerous substrates that can be used for the design of microstrip antennas, and their dielectric constants are usually in the range of $\left(2.2 \leq \varepsilon_{r} \leq 12\right)$. The substrates that are most desirables for antenna performance are thick substrates whose dielectric constants are in the lower end of the range. This provides better efficiency, larger bandwidth, and loosely bound fields for radiation into space, but at the expense of larger element size. On the other hand, the microwave circuit attached to the antenna requires thin substrate with high dielectric constant since this ensures tightly bound fields. Hence the undesired radiation and coupling can be minimized. In addition the microwave circuit size can be reduced.

Since microstrip antennas are integrated with the circuit in our module, a compromise has to be reached between good antenna performance and circuit design. The microstrip substrate 
Proceedings of the $\mathbf{2}^{\text {nd }}$ ICEENG Conference, 23-25 Nov. 1999



whose parameters are given in the previous section was found to represent the optimum compromise.

A computer program is developed in order to design the MPA and to calculate its parameters The equations used in the design are those given elsewhere $[3,4]$ and are summarized as follows:

1- The width $(w)$ of the patch antenna is given by:

$$
w=\frac{\lambda}{2}\left(\frac{\varepsilon_{r}}{2}\right)^{-1 / 2}
$$

where $\lambda$ is the free-space wavelength.

The width was found to be $40.02919 \mathrm{~mm}$.

2-The effective dielectric constant $\varepsilon_{\text {reff }}$ is given by:

$$
\varepsilon_{\text {reff }}=\frac{\varepsilon_{r}+1}{2}+\frac{\varepsilon_{r}-1}{2}\left[1+12 \frac{h}{w}\right]^{-1 / 2}
$$

3-The length of the MPA is given by:

$$
L=\frac{\lambda_{g}}{2}-2 \Delta l
$$

where

$$
\Delta l=0.412 h \frac{\left(\varepsilon_{\text {reff }}+0.3\right)\left(\frac{w}{h}+0.264\right)}{\left(\varepsilon_{\text {reff }}-0.258\right)\left(\frac{w}{h}+0.8\right)}
$$

The length was found to be $30.53942 \mathrm{~mm}$

If the coordinate system shown in Fig. 5 is used, the E-plane and the H-plane patterns are given respectively as:

4- The E-plane pattern $F(\phi)$ is determined from:

$$
F(\phi)=\frac{\sin \left(\frac{k h}{2} \cos \phi\right)}{\frac{k h}{2} \cos \phi} \cos \left(\frac{k L_{e}}{2} \sin \phi\right)
$$

where $k=2 \pi / \lambda$

5- The H-plane pattern $F(\theta)$ is determined from

$$
F(\theta)=\frac{\sin \left(\frac{k h}{2} \sin \theta\right)}{\frac{k h}{2} \sin \theta} \sin \theta
$$

The theoretical and experimental patterns are shown in Fig. 4.

6- The radiation resistance $\left(R_{r}\right)$ is given by:

$$
R_{r}=\frac{120 \pi^{2}}{I_{1}}
$$

where

$$
I_{1}=\int_{0}^{\pi} \sin ^{2}\left(\frac{k w \cos \theta}{2}\right) \tan ^{2} \theta \sin \theta d \theta
$$

7- the input impedance $Z_{\text {in }}(x)$, of the antenna is:

$$
Z_{\text {in }}(x)=\frac{1}{2} R_{r} \cos ^{2}(\beta x)
$$

where $x$ is the location of the feedpoint relative to the patch corner. 
8 - the directivity $D$ is given by:

$D=\frac{w^{2}: \pi^{2}}{I_{1}, \lambda^{2}}$

The effective gain is given by

$$
G=\eta D
$$

where $\eta$ is the antenna efficiency.

9- The beamwidth in the H-plane, $\theta_{B H}$, and that in the E-plane, $\theta_{B E}$, are given respectively as [3]:

$$
\begin{aligned}
& \theta_{B H}=2 \cos ^{-1}\left(\frac{1}{2+k_{O} w}\right)^{1 / 2} \\
& \theta_{B E}=2 \cos ^{-1}\left(\frac{7.03 \lambda_{O}^{2}}{4\left(3 L_{e}^{2}+h^{2}\right) \pi^{2}}\right)^{1 / 2}
\end{aligned}
$$

10- the bandwidth is given by [2] :

$$
B W=3.77 \frac{\varepsilon_{r}-1}{\varepsilon_{r}^{2}} \frac{h}{\lambda}
$$

The computed bandwidth is $0.45 \%$.

The computed E-plane and $\mathrm{H}$-plane patterns together with the measured patterns are given in Figs. 4 and 5 respectively. A good agreement is indicated between the computed and the measured patterns. However, there are some differences in the E-plane primarily near grazing and in the region below the ground plane. The differences near grazing are attributed to the fact that the dielectric material of the substrate is assumed to be truncated in the model The differences in the back region are because the model assumes an infinite ground plane. The shape of the H-plane pattern are not affected significantly by the dielectric cover or the edges. The computed radiation resistance $R_{r}$ is $224.5 \Omega$. The location of the feed is chosen such as the input impedance is $50 \Omega$ to facilitate matching. The theoretical directivity was $7.98 \mathrm{~dB}$ whereas the measured one was $7.2 \mathrm{~dB}$. The E-plane and H-plane beamwidths are $168.626^{\circ}$ and $117.1558^{\circ}$ respectively.

\section{Conclusions}

An active integrated antenna module is designed and implemented. This module comprises a high-gain amplifier, a 3-dB hybrid coupler and a patch antenna. The module is implemented and tested successfully in the NRC. This module is implemented using the microstrip-line technology. The designed module can be used in high-performance aircraft, spacecraft, and missile applications where size, weight, cost, performance, ease of installation and aerodynamic profiles are constraints.

The possible applications of the designed module include also mobile radio and wireless communications

\section{REFERENCES}

[1] Itoch, T. "Quasi-optical microwave circuits for wireless applications" Microwave J, Vol. 38, No. 1, pp. 64-85, Jan. (1995).

[2] James, J., Hall, P. and Wood, C,Microstrip Antenna Theory and Design, Stevenaque, U.K., Peregrinus, (1981). 
[3] Bahl, L. J. and Bhatra, P.,Microstrip Antenna, Artech House, Deham, MA, (1980).

[4] Lee, K. F. and Chen, W, Advances in microstrip and printed antennas, John Wiely\& Sons Inc., (1997).

[5] Cryan, M., Hall, P., Tsang, S. and Sho, J. "Integrated active antenna with full duplex operation" IEEE Trans. on Microwave Theory \& Tech., Vol. 45, No. 10, Oct., (1997).

[6] Fusco, V. "Series feedback integrated active microstrip antenna synthesis and characterization" Electron. Lett., Vol. 28, No. 1, Jan. (1992).

[7] Edwards, T. C., Foundations for microstrip circuit design, John Wiley \& Sons Inc., (1992).

[8] El-Motaafy, H. et al. " Computer-aided design and nonlinear analysis of a $19 \mathrm{GHz}$ microstrip amplifier ', ICM'95, The $7^{\text {th }}$ International Conference on Microelectronics, Kuala Lumpour, Malysio, Dec., (1995).

[9] El-Motaafy, $\mathbf{H}$. et al. "Design and analysis of 2-4 GHz broadband high-gain microstrip amplifier " The $4^{\text {th }}$ Saudi Engineering Conference, Jeddah, K.S.A., Nov. (1995).

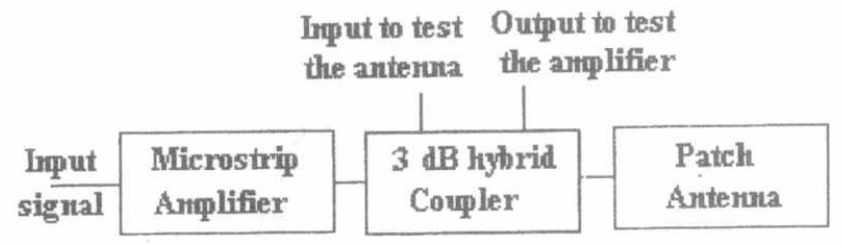

Fig. 1. The block diagram of the module

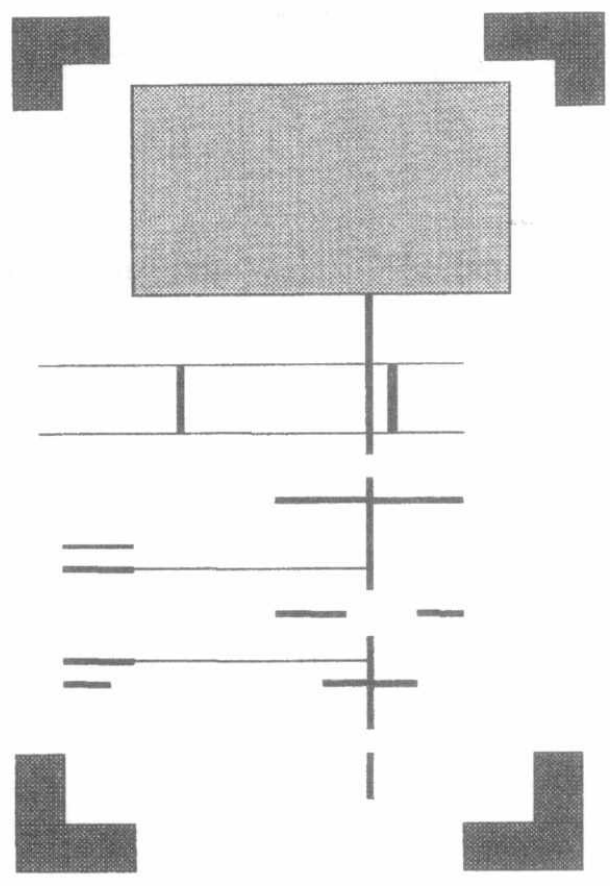

Fig. 2 Layout of the module 
Proceedings of the $2^{\text {nd }}$ ICEENG Conference, 23-25 Nov. 1999

\begin{tabular}{|l|l|}
\hline $\mathrm{AW}-5$ & 6 \\
\hline
\end{tabular}

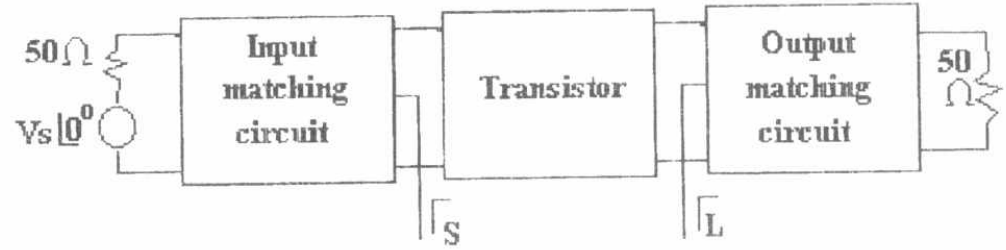

Fig. 3. The block diagram of the microwave amplifier



Fir 4 The E-plane adition patlen ( - computed, ( - ) measured

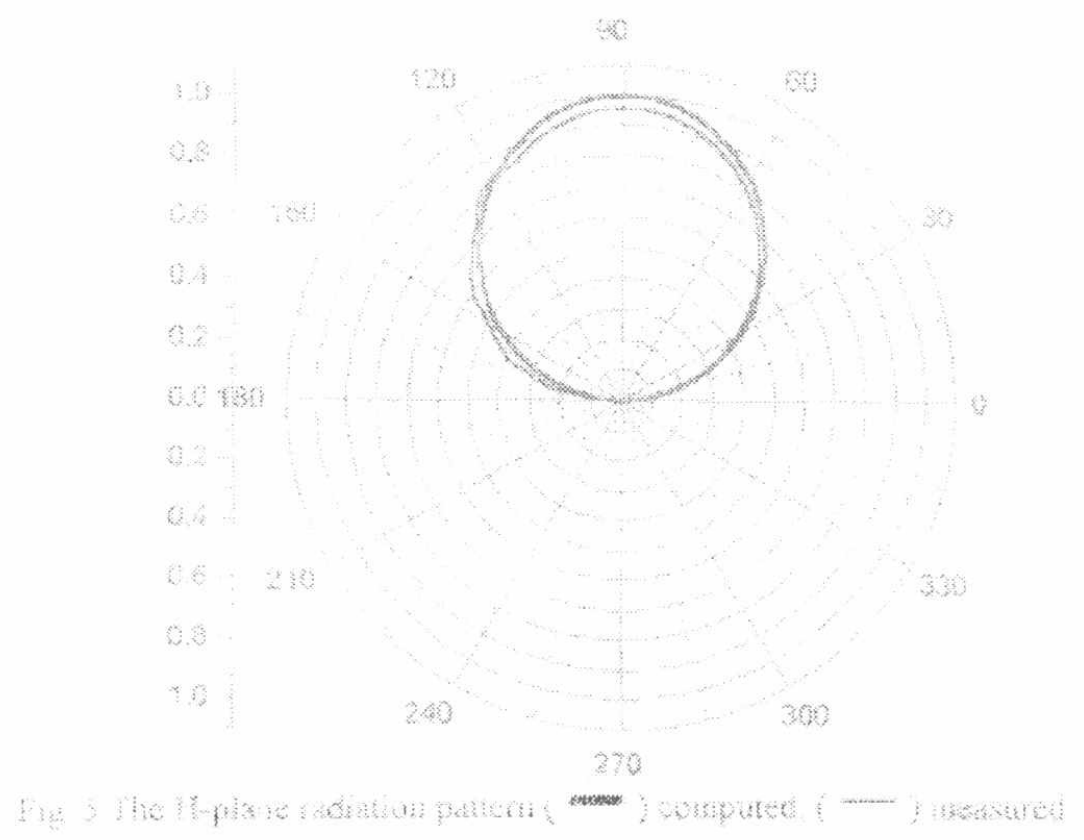

